\title{
Developing the emotional intelligence of senior preschoolers through various types and forms of social practice
}

\author{
Tatiana D. Savenkova ${ }^{1}$ * \\ ${ }^{1}$ Moscow City University, Institute of Pedagogics and Psychology of Education, Department of \\ Psychology, Moscow, Russia
}

\begin{abstract}
The article presents the results of an empirical study aimed at assessing the effectiveness of the author's program for developing the emotional intelligence of senior preschoolers through various types and forms of social practice. Like other personality traits, the emotional intelligence of senior preschoolers manifests itself and develops in various types of social practice. One of the most widespread options is different joint activities with peers and adults. Joint activity with peers and adults based on more complex forms of interaction is regarded as the most accessible option for the social practice of children. The article presents a model of children's emotional intelligence that serves as a basis of the author's program of its development in senior preschoolers through various types and forms of social practice. The diagnostic assessment of the emotional intelligence of senior preschoolers was conducted with the use of the author's methodology developed for teachers and psychologists of preschool educational organizations. Teachers of preschool educational organizations participated in the study as experts assessing the emotional intelligence of children. The results were determined based on the average values provided by each expert for each child and indicator. The study has demonstrated that an important condition for the effective development of the emotional intelligence of senior preschoolers is specially organized social practice based on the child's gradual mastering of the basic components of social intelligence. To gradually improve the emotional intelligence of senior preschoolers, it is necessary to include them in more complex joint activities with peers and adults.
\end{abstract}

Keywords: emotional intelligence, emotional development, social practice of senior preschoolers, interaction with peers and adults, joint activity

\section{Introduction}

Like other integrative personality traits, the emotional intelligence of senior preschoolers manifests itself and develops in various types of social practice. Some scholars consider the task of developing the child's emotional intelligence within the framework of studying

\footnotetext{
* Corresponding author: savenkovatd@mgpu.ru
} 
giftedness, cognitive and academic success $[1,2]$. One of the most widespread variants of social practice is different joint activities with peers and adults.

Therefore, an important task of educational activities in kindergartens is the professional organization of various types and forms of social practice, which allows promoting the development of the child's emotional intelligence. The study aims at testing the effectiveness of the above-mentioned educational program based on special social practice for senior preschoolers, improving their emotional intelligence and social competence. The research hypotheses are as follows:

- An important condition for the effective development of the emotional intelligence of senior preschoolers is social practice organized by teachers and based on the gradual mastering of its basic components (understanding the emotions and motives of other's social behavior; the adequate expression and regulation of one's emotions when interacting with other people; the management of one's emotions and social behavior);

- The organized inclusion of children in more complex joint activities with peers and adults (from joint-individual to joint-interacting) is important for the further development of the emotional intelligence of senior preschoolers.

\section{Methods}

The general research scheme can be described as classical. In the course of the study, we compared the data obtained in both experimental and control groups. According to this approach, the first stage (conventionally called "diagnostic") and the final stage (conventionally called "control") used similar diagnostic tools to assess the development of emotional intelligence in children from the experimental and control groups.

During the next stage of the study (conditionally called "forming"), senior preschoolers in the control group used traditional educational means that should stimulate their emotional intelligence and solve other educational tasks. In contrast to the control group, the experimental group was taught using a specially developed model of educational activity at the "forming" stage of the study. This program was designed for the purposeful improvement of the emotional intelligence of senior preschoolers through various types and forms of social practice. According to the general structure of the study, the results of developing the social intelligence of senior preschoolers from the experimental and control groups were compared at the final stage of the study (conditionally called "control").

The selection of the respondents consisted of 250 senior preschoolers who were divided into several groups. The children who participated in the study attended senior and preparatory groups in various preschool educational organizations in Moscow. The experimental groups included 124 children, the control groups comprised 126 children.

The diagnostic assessment of the social intelligence of senior preschoolers was conducted using the author's methodology developed for teachers of preschool educational organizations [3]. Teachers of preschool educational organizations participated in the study as experts assessing the development of social intelligence in children; the average values for each child and each indicator were used as the results.

\section{Results}

The results of the diagnostic examination of senior preschoolers from the experimental and control groups according to the development of their emotional intelligence at the first ("diagnostic") and final ("control") stages of the study are presented in Table 1. These data clearly show that children in the experimental and control groups had almost identical levels of emotional intelligence at the initial ("diagnostic") stage of the experiment. 
Following the "diagnostic" stage, the second ("forming") stage of empirical research introduced the author's program to the experimental group. Its main objective was to develop the emotional intelligence of senior preschoolers. In the control groups, the tasks of stimulating children's emotional intelligence were solved traditionally, i.e. spontaneously, without any specialized programs.

The program we developed contains concepts of emotional intelligence as an independent psychological construct and its relevant content provided by modern psychologists from various scientific schools and different countries [4-6]. An important source for developing this educational program aimed at improving the emotional intelligence and social competence of preschoolers was the works of scientists from around the world who studied various aspects of its manifestation and development [7-11].

The experimental program implemented at the forming stage of the study in the experimental groups included two relatively independent parts:

- The first ("basic") part consisted of special classes on improving the emotional intelligence of senior preschoolers based on the material of various subject areas provided for by the state educational standard. Using special methodological techniques, as well as joint games and classes, teachers worked on interaction skills and adequate emotional responses;

- The second part included almost all everyday life activities of children in the kindergarten. It covered the entire range of traditional activities included in the basic educational programs of preschool educational organizations, as well as spontaneously arising situations of social interaction with other people, both children and adults.

The main distinction of the program is the absence of a strict algorithm for planning and conducting training sessions to improve the emotional intelligence of children. A variety of individual tasks, the general structure of classes, the inclusion of role-playing and theater games, the application of training techniques ensured a steady interest in classes not only among children but also among their teachers. Particular attention was paid to the joint activities of children and adults. The active involvement of adults in the process of interaction and game-based co-creation with children was regarded as one of the most important tools for improving the emotional intelligence of senior preschoolers. In these conditions, effective work requires a teacher of high qualifications and presupposes skills to invent, improvise and combine. This is necessary for the effective inclusion of game-based situations of cooperation and joint creativity in the daily social practice of senior preschoolers.

The general level of the child's social development and the basic features of the emotional sphere (emotional intelligence) are being manifested and improved in all spheres of life and all types of activity. The educational courses provided by the program, traditional and the author's stories developed especially for children from the experimental groups, games and tasks are not the only source of developing and improving their emotional intelligence. However, this program and similar training courses are capable of ensuring the purposefulness and effectiveness of the processes developing the emotional intelligence of senior preschoolers.

Considering the basic features of emotional intelligence, we have determined the main blocks for forming special classes within the framework of the program. These classes should be based on the model of joint games or other types of joint activities for children. The program mainly included training exercises, both the author's and those found in a large number of special psychological and pedagogical literature. In addition, we involved practicing teachers in the development (based on a wide range of subject materials) of methods and educational tasks aimed at improving the emotional intelligence of senior preschoolers. 
The content and main blocks of the experimental program for improving the emotional intelligence of senior preschoolers in the course of social practice are presented in Figure 1.

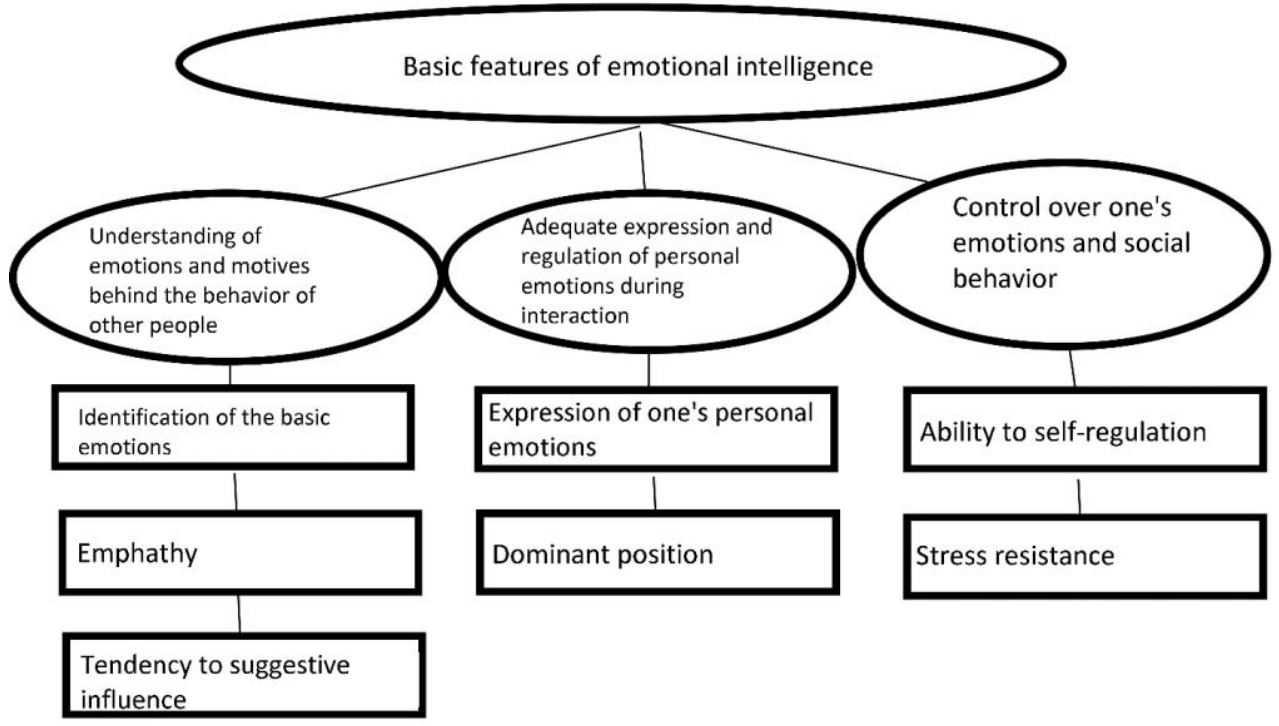

Fig. 1. The theoretical model of the emotional intelligence of preschoolers.

In modern scientific works on preschool pedagogy and child psychology, the collective creativity of preschool children is considered an organized activity of interacting individuals [12]. The Russian pedagogy proceeds from the fact that the joint activities of children improve their skills of cooperation and counter-balance the egocentrism typical of that age. By participating in joint activities, children master elementary skills to overcome their immediate desires and gain experience of acting in the interests of other people.

Under the theory of activity developed in Russian science, the structure of joint activity includes the following components: common goals, common motivation, the distribution of responsibilities, the integration of individual efforts, management, the overall result and reflection [13]. The common goal or the main element of this structure is usually a common result. A newly formed group actor (in this case, a group of preschool children) seeks to achieve it.

Depending on the interaction of children and their specific participation in the joint activity (as well as the teacher's participation), as well as the joint interaction of children, can be considered in the form of five most common options:

- Activities of children under the guidance of adults;

- Joint activities of children and adults;

- Joint activities of a group of children under the guidance of adults;

- Joint activities of children with peers without the participation of adults but on their instructions;

- Independent and spontaneous joint activity of children.

\section{Discussion}

At the final ("control") stage of the experiment aimed at assessing the effectiveness of the proposed program of intensive improvement of the emotional intelligence of senior preschoolers, we tested various types of social practice and forms of interaction between 
children and adults or peers in the context of special training sessions. The results obtained at this stage of the study allowed to distinguish between children from the experimental and control groups after completing the forming stage of the experiment. The results obtained by children from the experimental and control groups at the "diagnostic" and "control" stages of the study are presented in Table 1.

Table 1. Results of the diagnostic examination of senior preschoolers from the experimental and control groups according to the development of their emotional intelligence.

\begin{tabular}{|c|c|c|c|c|c|}
\hline Study stages & $\begin{array}{c}\text { Extremely } \\
\text { high }\end{array}$ & High & Moderate & Low & $\begin{array}{c}\text { Extremely } \\
\text { low }\end{array}$ \\
\hline \multicolumn{7}{|c|}{ Experimental groups } \\
\hline Diagnostic & $1 \%$ & $12 \%$ & $72 \%$ & $12 \%$ & $2 \%$ \\
\hline Control & $10 \%$ & $30 \%$ & $54 \%$ & $6 \%$ & $0 \%$ \\
\hline Control & $2 \%$ & $11 \%$ & $74 \%$ & $11 \%$ & $2 \%$ \\
\hline & $2 \%$ & $13 \%$ & $75 \%$ & $8 \%$ & $2 \%$ \\
\hline
\end{tabular}

The comparison of the data obtained at the "diagnostic" and "control" stages of the study clearly indicates that there was only $1 \%$ of children with an "extremely high" level of emotional intelligence at the first ("diagnostic") stage of the study in the experimental groups. At the final ("control") stage, the number of such children in the experimental groups was already $10 \%$. At the same time, children with "low" and "extremely low" levels of emotional intelligence were almost equally divided at the initial stage of the empirical study $-12 \%$ and $1 \%$ in the experimental groups; $11 \%$ and $2 \%$ in the control groups. On the contrary, the results differed at the final ("control") stage of the study. In the experimental groups, there were no children with an "extremely low" level of emotional intelligence and only $6 \%$ of children with a "low" level. In the control groups, there were $2 \%$ of children with an "extremely low" level of social intelligence and $8 \%$ of preschoolers with a "low" level.

It is worth mentioning that senior preschoolers who were part of the control groups also demonstrated positive dynamics in the development of emotional intelligence but their achievements were more modest in comparison with the experimental group. The results obtained can prove the effectiveness of the above-mentioned program for developing the emotional intelligence of senior preschoolers, implemented in the context of various types of social practice and using various forms of interaction between children and adults or peers.

\section{Conclusion}

The study has demonstrated that an important condition for the effective development of the emotional intelligence of senior preschoolers is specially organized social practice in educational institutions based on the child's gradual mastering of the basic components of social intelligence and sensory experiences obtained in the course of social interaction. To gradually improve the emotional intelligence of senior preschoolers, it is necessary to include them in more complex joint activities with peers and adults.

The emotional intelligence of children develops in all types of activities and through all the options for social practice, therefore further studies of this issue can bring prominent results in the context of various types of children's social practice (in a family, in spontaneous children's interactions with peers, etc.). 


\section{References}

1. N. Meijs, A.H.N. Cillessen, R.H.J. Scholte, Journal of Youth and Adolescence, 39, 6272 (2010). https://doi.org/10.1007/s10964-008-9373-9

2. A.I. Savenkov, S.I. Karpova, E.I. Sukhova, Psychology, 55(2), 74 (2018). Accessed on: December 20, 2020. [Online]. Available:

https://www.researchgate.net/publication/331497658_Model_of_development_of_chil dren's_giftedness_in_the_Russian_education_system

3. T.D. Savenkova, Vestnik Moskovskogo Gorodskogo Pedagogicheskogo Universiteta, Series: Pedagogika i Psikhologiya, 3(41), 47-53 (2017)

4. R. Bar-On, Emotional intelligence and self-actualization. Emotional intelligence in everyday life (Psychology Press, New York, 2001)

5. J.D. Mayer, P. Salovey, Emotional Intelligence. Electronic Journal of Research in Educational Psychology, 6(2)(15), 421-436 (2008)

6. A.I. Savenkov, Journal of Modern Foreign Psychology, 7(2), 7-15 (2018). https://doi.org/10.17759/jmfp.2018070201

7. S. Ang, L. van Dyne (Eds.), Handbook of cultural intelligence: Theory, measurement, and applications (Routledge, New York, 2015)

8. S. Pabian, H. Vandebosch, Journal of Early Adolescence, 36(2), 145-170 (2016)

9. K.A. Pekaar, Personality and Individual Differences, 120, 222-233 (2018). https://doi.org/10.1016/j. paid.2017.08.045

10. M. Anwer, Pakistan Journal of Psychology, 48(2), 3-20 (2017). Accessed on: May 16, 2018. [Online]. Available:

http://search.ebscohost.com/login.aspx?direct=true\&db=aph\&AN=129038835\&lang=r u\&site= $=$ host-live

11. I. Esnaola, Anales de Psicología, 33(2), 327-333 (2017)

12. T.S. Komarova, A.I. Savenkov, Doshkolnaya pedagogika. Kollektivnoe tvorchestvo detei [Preschool pedagogy. The joint creative activity of children] (Professionalnoe obrazovanie, Moscow, 2020)

13. A.L. Zhuravlev, Psikhologiya sovmestnoi deyatelnosti [The psychology of joint activity] (Institut psikhologii RAN, Moscow, 2005) 